Cochrane Database of Systematic Reviews

\title{
Lisuride versus bromocriptine for levodopa-induced complications in Parkinson's disease (Review)
}

Clarke C E, Speller J M, Clarke CE

Clarke C E, Speller J M, Clarke CE.

Lisuride versus bromocriptine for levodopa-induced complications in Parkinson's disease.

Cochrane Database of Systematic Reviews 1999, Issue 1. Art. No.: CD001514.

DOI: 10.1002/14651858.CD001514.

www.cochranelibrary.com 
TABLE OF CONTENTS

HEADER 1

ABSTRACT

BACKGROUND

OBJECTIVES

METHODS

RESULTS

DISCUSSION

AUTHORS' CONCLUSIONS

ACKNOWLEDGEMENTS

REFERENCES

CHARACTERISTICS OF STUDIES

DATA AND ANALYSES

Analysis 1.1. Comparison 1 Lisuride v bromocriptine, Outcome 1 Columbia rating scale - total score. WHAT'S NEW

HISTORY

DECLARATIONS OF INTEREST

INDEX TERMS 
[Intervention Review]

\section{Lisuride versus bromocriptine for levodopa-induced complications in Parkinson's disease}

E Clarke C1, M Speller J11, C E Clarke²

1Not specified. 2Department of Neurology, City Hospital NHS Trust, Birmingham, UK

Contact address: C E Clarke, Department of Neurology, City Hospital NHS Trust, Dudley Road, Birmingham, West Midlands, B18 7QH, UK.c.e.clarke@bham.ac.uk.

Editorial group: Cochrane Movement Disorders Group

Publication status and date: Edited (no change to conclusions), published in Issue 1, 2010.

Citation: Clarke C E, Speller J M, Clarke CE. Lisuride versus bromocriptine for levodopa-induced complications in Parkinson's disease. Cochrane Database of Systematic Reviews 1999, Issue 1. Art. No.: CD001514. DOI: 10.1002/14651858.CD001514.

Copyright @ 2010 The Cochrane Collaboration. Published by John Wiley \& Sons, Ltd.

\section{A B S T R A C T}

\section{Background}

Long-term levodopa therapy in Parkinson's disease is associated with the development of motor complications including abnormal involuntary movements and a shortening response to each dose (wearing off phenomenon). It is thought that dopamine agonists can reduce the duration of immobile off periods and the need for levodopa therapy whilst maintaining or improving motor impairments and only minimally increasing dopaminergic adverse events.

\section{Objectives}

To compare the efficacy and safety of adjunct lisuride therapy versus bromocriptine in patients with Parkinson's disease, already established on levodopa and suffering the long-term complications of therapy.

\section{Search methods}

Electronic searches of MEDLINE, EMBASE and the Cochrane Controlled Trials Register. Handsearching of the neurology literature as part of the Cochrane Movement Disorders Group's strategy. Examination of the reference lists of identified studies and other reviews. Contact with Cambridge Laboratories, Roche Products Limited and Sandoz Limited.

\section{Selection criteria}

Randomised controlled trials of lisuride versus bromocriptine in patients with a clinical diagnosis of idiopathic Parkinson's disease and long-term complications of levodopa therapy.

\section{Data collection and analysis}

Data was abstracted independently by each author and differences settled by discussion.

\section{Main results}

Only one randomised cross-over trial including 20 patients has compared lisuride with bromocriptine as adjunct therapy in Parkinson's disease. Both lisuride and bromocriptine improved motor fluctuations with no significant differences between the agonists. However, this conclusion is based on an unvalidated 4 point rating scale which could only record positive outcomes. This, combined with the small size of the trial, suggests that firm conclusions on motor fluctuations should not be drawn. Lisuride and bromocriptine produced similar benefits in parkinsonian impairments according to the Columbia Rating Scale. Adverse events were similar with the two agonists and no withdrawals were reported from either drug. 


\section{Authors' conclusions}

The small size of this study and other methodological problems do not allow any firm conclusions to be drawn regarding the efficacy and safety of lisuride compared with bromocriptine in advanced Parkinson's disease with motor complications. 


\section{B A C K G R O U N D}

Over 20 years after its introduction, levodopa remains the most effective therapy in Parkinson's disease. However, with longterm treatment, patients develop side effects comprised of motor and psychiatric complications. The former consist of involuntary writhing movements of the limbs and trunk (choreoathetosis), painful cramps often affecting the feet (dystonia) and a shortened response to each dose of levodopa (end-of-dose deterioration). These affect $50 \%$ of patients after 6 years of therapy (Rajput 1984 ) and $100 \%$ of young onset patients (Quinn 1986). In contrast, more recent work found motor complications in only $16 \%$ after 5 years of immediate or slow release levodopa therapy (Block 1997) suggesting we are now more cautious in our use of this agent.

An alternative treatment in Parkinson's disease is the dopamine agonist class of drug. These act directly on post-synaptic dopamine receptors in the striatum and so they do not require conversion into dopamine, as does levodopa. Unfortunately, they are less effective in clinical practice than expected, although they generate fewer motor complications when used as long-term monotherapy (e.g. Stern and Lees 1986; PDRG 1993). The use of dopamine agonists in newly diagnosed patients will be the subject of further Cochrane reviews.

Lisuride is an ergoline-based dopamine agonist like bromocriptine and pergolide. In a randomised controlled trial of 90 patients with early Parkinson's disease, over 4 years, lisuride monotherapy produced less dyskinesia and end-of-dose deterioration than levodopa, although it was less effective on parkinsonian disability (Rinne 1989). It was also hoped that, when added later in the course of the disease, lisuride would reduce off periods by virtue of a levodopa sparing effect and generate less motor complications than levodopa over the long-term.

A number of open label studies of lisuride as adjunct therapy to levodopa suggested it is capable of reducing off time. The present study has therefore been performed to provide a systematic review of all randomised controlled trials of adjunct lisuride therapy versus the active comparator bromocriptine in Parkinson's disease. A separate Cochrane review covers the effects of lisuride versus placebo.

\section{O B JECTIVES}

To compare the efficacy and safety of adjuvant lisuride versus bromocriptine in patients with Parkinson's disease, already established on levodopa and suffering from motor complications.

\section{METHODS}

\section{Criteria for considering studies for this review} Types of studies

All randomised trials comparing lisuride with bromocriptine were considered for inclusion in the study.

\section{Types of participants}

Patients with a clinical diagnosis of idiopathic Parkinson's disease who had developed long-term motor complications of dyskinesia and/or end-of-dose deterioration. All ages were included. Any duration of levodopa therapy was included.

\section{Types of interventions}

Oral lisuride therapy or bromocriptine. Trial durations of greater than 4 weeks were included.

\section{Types of outcome measures}

1. Improvement in the time patients spend in the immobile 'off' state.

2. Changes in dyskinesia rating scales and the prevalence of dyskinesia.

\section{Changes in parkinsonian rating scales.}

Many such rating scales exist. The Hoehn and Yahr scale (Hoehn and Yahr 1967) is usually used to classify the stage of the disease, but it is often used to follow the response to drug therapy. More recently, the Unified Parkinson's Disease Rating Scale (UPDRS 1987) has been used to score various disabilities and impairments due to the disease. Individual items from these scales were also used to provide more meaningful outcomes for patients reading this review.

\section{Reduction in levodopa dose.}

5. Number of withdrawals due to lack of efficacy and/or side-effects.

\section{Search methods for identification of studies}

1. The review was based on the search strategy of the Movement Disorders Group. This included computerised searches of MEDLINE and EMBASE and hand searching of appropriate neurology journals. Relevant trials were included on the Group's specialised register of randomised controlled trials. Further details are available in the Group's module on the Cochrane Database of Systematic Reviews.

2. The Cochrane Controlled Trials Register was also searched for relevant trials.

3. The reference lists of located trials and of other lisuride and bromocriptine reviews were searched.

4. Additional assistance was provided by the drug manufacturer Cambridge Laboratories and Sandoz Limited.

\section{Data collection and analysis}

The two authors (CC, JS) independently assessed the studies identified by the search strategy. Disagreements about inclusions were resolved by discussion. The full papers were assessed for methodological quality by recording the method of randomisation and blinding, whether an intention to treat analysis was used and the number of patients lost to follow up.

Eligible data was abstracted onto a standard form by both authors independently, checked for accuracy and amalgamated. Since Review Manager version 3 does not support non-parametric methods for combining categorical variables, the results of parkinsonian rating scales were included as descriptions of results. 


\section{RESULTS}

\section{Description of studies}

Only two trials were found comparing lisuride with bromocriptine in later Parkinson's disease with motor complications. Le Witt 1982 contained some patients who had not been exposed to levodopa, so it was excluded from the current review. Laihinen 1992 was a small cross-over study in 20 patients. The first period of the study was used for the purposes of this review.

\section{Risk of bias in included studies}

Laihinen 1992 contains no details about the method of randomisation or concealment of allocation, thus selection bias cannot be excluded. In this study, patients and clinicians recording observations were blind to the allocation of medication, so performance and attrition bias are unlikely. No information on the method of data analysis was given or whether an intention-to-treat analysis was used. Therefore, detection bias cannot be excluded. The maximum duration of either arm of the study was only 12 weeks.

\section{Effects of interventions}

Only one randomised controlled trial comparing lisuride with bromocriptine in levodopa-treated patients with off periods has been performed (Laihinen 1992). This small study included only 20 patients and the first arm of the cross-over design lasted for only 12 weeks at the most.

In the report of Laihinen 1992, data on motor fluctuations were not given separately for the two arms of the cross-over study. It is stated that both lisuride and bromocriptine improved fluctuations, as rated on their ad hoc 4 point scale, and that there were no significant differences between the agonists in this respect.

Peak-dose dyskinesia was said to deteriorate but dystonia improved with both agonists, although no data was presented to confirm this.

Lisuride and bromocriptine gave rise to similar improvements in impaiment due to Parkinson's disease according to the Columbia Rating Scale (see Table of Comparisons - Other Data). No significant difference was found in the improvement in the total Columbia Scale between the two agonists.

Levodopa dose was held stable throughout the study, unlike some other adjunct agonist trials.

Adverse events were combined for both arms of the trial. In view of the small numbers in the study $(n=19$ in each arm for adverse events report), the prevalence of such events should be interpreted with caution. However, the prevalence of dopaminergic side-effects appeared similar with each agonist across both arms (e.g. nausea - 26\% lisuride, $21 \%$ bromocriptine; postural hypotension - $5 \%$ lisuride, $21 \%$ bromocriptine; hallucinations - $5 \%$ with each agonist). No withdrawals from medication were reported.

\section{DISCUSSION}

Only one trial comparing lisuride with bromocriptine as adjunct therapy in Parkinson's disease is available (Laihinen 1992). This was a small cross-over trial including only 20 patients. The results should be interpreted with extreme caution in view of the study's size.

Both lisuride and bromocriptine improved motor fluctuations with no significant differences between the agonists. However, this conclusion is based on an unvalidated 4 point rating scale which could only record positive outcomes. This combined with the small size of the trial suggests firm conclusions on motor fluctuations should not be drawn.

Lisuride and bromocriptine had similar effects on parkinsonian impairments according to the Columbia Rating Scale and adverse events were similar between the two agonists, with no withdrawals reported from either drug. However, the small numbers of patients in this study and its short duration suggest that caution should be exercised in drawing conclusions about such efficacy and safety comparisons.

\section{AUTHORS' CONCLUSIONS}

\section{Implications for practice}

Only one randomised controlled trial has compared lisuride with bromocriptine as adjunct therapy in later Parkinson's disease. This small study $(n=20)$ showed similar effects on fluctuations and parkinsonian impairments with comparable adverse events with each agonist. However, the size of this study is such that it is impossible to firmly conclude equivalence between the agonists.

\section{Implications for research}

Incomplete Reporting

It is suggested that the CONSORT (Consolidated Standards of Reporting Trials) reporting standards are used by colleagues in the future (CONSORT 1996). These guidelines have been adopted by several leading general interest and neurology journals. They consist of a checklist of 21 items that include descriptions of the randomization procedure and allocation concealment, the mechanisms of blinding/masking and the number of people lost to follow-up. The adoption of these guidelines would greatly assist in performing systematic reviews and would improve the quality of individual trial reports.

\section{Parkinson's Disease Rating Scales}

Trials in the future should adopt a more standardised battery of tests including a universally accepted, validated and reliable rating scale (at present, the Unified Parkinson's Disease Rating Scale; UPDRS 1987), 30 minute epoch 'on'/'off' diary cards, levodopa dose reduction and adverse events. Although UPDRS dyskinesia ratings should be used at present, a better validated dyskinesia scale is required.

\section{Further Trials}

Further studies are required to assess whether lisuride has any advantages in efficacy or safety over bromocriptine.

Another Cochrane review examines whether lisuride is superior to placebo as adjunct therapy in Parkinson's disease.

\section{ACKNOWLEDGEMENTS}

The authors wish to thank the drug manufacturers Cambridge Laboratories, Roche Products Limited and Sandoz Limited for their valuable assistance. 


\section{RE F E R E N CE S}

\section{References to studies included in this review}

Laihinen 1992 \{published data only\}

Laihinen A, Rinne UK, Suchy I. Comparison of lisuride and bromocriptine in the treatment of advanced Parkinson's disease. Acta Neurologica Scandinavica 1992;86:593-595.

\section{References to studies excluded from this review \\ LeWitt 1982 \{published data only\}}

LeWitt PA, Gopinathan G, Ward CD, Sanes JN, Dambrosia JM, Durso R, Calne DB. Lisuride versus bromocriptine treatment in Parkinson's disease: a double-blind study. Neurology 1982;32:69-72.

\section{Additional references}

Block 1997

Block G, Liss C, Reines S, Irr J, Nibbelink D, The CR First Study Group. Comparison of immediate-release and controlledrelease carbidopa/levodopa in Parkinson's disease. Eur Neurol 1997;37:23-27.

\section{CONSORT 1996}

Begg C, Cho M, Eastwood S, Horton R, Moher D, Olkin I, Pitkin R, Rennie D, Schulz KF, Simel D, Stroup DF. Improving the quality of reporting of randomized controlled trials: the CONSORT statement. JAMA 1996;276(8):637-639.

\section{CHARACTERISTICS OF STUDIES}

Characteristics of included studies [ordered by study ID]

\section{PDRG 1993}

Parkinson's Disease Study Group in the United Kingdom. Comparison of the therapeutic effects of levodopa, levodopa and selegiline, and bromocriptine in patients with early, mild Parkinson's disease: three year interim report. BMJ 1993;307:469-472.

\section{Quinn 1986}

Quinn N, Critchley P, Parkes D, Marsden CD. When should levodopa be started?. 985-986.

\section{Rajput 1984}

Rajput AH, Stern W, Laverty WH. Chronic low-dose levodopa therapy in Parkinson's disease. Neurology 1984;34:991-996.

\section{Rinne 1989}

Rinne UK. Lisuride, a dopamine agonist in the treatment of early Parkinson's disease. Neurology 1989;39(3):336-9.

\section{Stern and Lees 1986}

Stern G, Lees AJ. Long-term effects of bromocriptine given to de novo patients with idiopathic Parkinson's disease. Adv Neurol 1986;45:525-527.

\section{UPDRS 1987}

Fahn S, Elton RL and members of the UPDRS development committee. Unified Parkinson's Disease Rating Scale. In: Recent developments in Parkinson's disease. Eds: Fahn S, Marsden CD, Calne D, Goldstein M. Publ: Macmillan, New Jersey. Macmillan, New Jersey. 1987.

\section{Laihinen 1992}

$\begin{array}{ll}\text { Methods } & \text { Randomised, double-blind cross-over design. No details of method of randomisation given. } \\ & \text { Not clear whether intention-to-treat analysis. } \\ & \text { Titration by unblinded clinician. } \\ & \text { Outcomes assessed by blinded examiner. } \\ \text { Duration - variable } 4-8 \text { week titration followed by } 4 \text { weeks stable dose; up to } 2 \text { weeks wash-out then 4-8 } \\ \text { week titration with second agonist and } 4 \text { week stable dose. }\end{array}$

Outcomes 
Laihinen 1992 (Continued)

Adverse events.

\section{Notes}

\section{Risk of bias}

\begin{tabular}{lll}
\hline Bias & Authors' judgement & Support for judgement \\
\hline Allocation concealment? & Unclear risk & B - Unclear \\
\hline
\end{tabular}

Characteristics of excluded studies [ordered by study ID]

\begin{tabular}{ll}
\hline Study & Reason for exclusion \\
\hline LeWitt 1982 & $\begin{array}{l}\text { Mixed patient population: } 4 \text { not receiving levodopa at time of study and not all had long-term mo- } \\
\text { tor complications. }\end{array}$ \\
\hline
\end{tabular}

\section{DATA AND ANALYSES}

\section{Comparison 1. Lisuride v bromocriptine}

\begin{tabular}{|c|c|c|c|c|}
\hline Outcome or subgroup title & $\begin{array}{l}\text { No. of } \\
\text { studies }\end{array}$ & $\begin{array}{l}\text { No. of partici- } \\
\text { pants }\end{array}$ & Statistical method & Effect size \\
\hline 1 Columbia rating scale - total score & & & Other data & No numeric data \\
\hline
\end{tabular}

Analysis 1.1. Comparison 1 Lisuride v bromocriptine, Outcome 1 Columbia rating scale - total score.

\begin{tabular}{|c|c|}
\hline \multicolumn{2}{|c|}{ Columbia rating scale - total score } \\
\hline & \\
\hline Laihinen 1992 & $\begin{array}{l}\text { Improvement on lisuride from } 55.4(3.1) \text { to } 34.6 \text { (3.1); difference - } 20.8 \text {. } \\
\text { Improvement on bromocriptine from } 64.3 \text { (4.4) to } 48.1 \text { (5.4); difference - 16.2. } \\
\text { Means (standard error). }\end{array}$ \\
\hline
\end{tabular}

\section{WHAT'S NEW}

\begin{tabular}{lll}
\hline Date & Event & Description \\
\hline 14 November 2008 & Amended & Converted to new review format. \\
\hline
\end{tabular}

\section{HISTORY}

Review first published: Issue 2, 1999 


\begin{tabular}{lll}
\hline Date & Event & Description \\
\hline 25 November 1998 & $\begin{array}{l}\text { New citation required and conclusions } \\
\text { have changed }\end{array}$ & Substantive amendment \\
\hline
\end{tabular}

\section{DECLARATIONS OF INTEREST}

\section{None}

\section{N D X T ERMS}

\section{Medical Subject Headings (MeSH)}

Antiparkinson Agents [adverse effects] [ ${ }^{*}$ therapeutic use]; Bromocriptine [*therapeutic use]; Dyskinesia, Drug-Induced [*drug therapy] [etiology]; Levodopa [adverse effects]; Lisuride [ ${ }^{\star}$ therapeutic use]; Parkinson Disease [ ${ }^{\star}$ drug therapy]

\section{MeSH check words}

Humans 